\title{
Are cataracts associated with osteoporosis?
}

This article was published in the following Dove Press journal:

Clinical Ophthalmology

17 October 2013

Number of times this article has been viewed

\section{Arie Y Nemet ${ }^{\prime}$ \\ Joel Hanhart ${ }^{2}$ \\ Igor Kaiserman ${ }^{3,4}$ \\ Shlomo Vinker ${ }^{5,6}$}

'Department of Ophthalmology, Meir Medical Center, Kfar Saba,

2Department of Ophthalmology, Shaare Zedek Medical Center, Jerusalem, ${ }^{3}$ Department of Ophthalmology, Barzilai Medical Center, Ashkelon, ${ }^{4}$ Faculty of Health Sciences, Ben Gurion University, Be'er Sheba, ${ }^{5}$ Department of Family Medicine, Clalit Health Services, Rehovot, ${ }^{6}$ Department of Family Medicine, Tel Aviv University, Tel Aviv, Israel
Correspondence: Arie Y Nemet Department of Ophthalmology, Meir Medical Center, 59 Tchernichovsky Street, Kfar Saba 44299, Israel

Tel +97297472154

Fax +97297678370

Email nemet.arik@gmail.com
Background: Calcium is considered an important factor in the development of both osteoporosis and cataract. This study evaluated the association between osteoporosis and cataracts.

Objective: To evaluate the prevalence of osteoporosis among patients undergoing cataract surgery, and the association between the two.

Patients and methods: This was a retrospective observational case-control study, conducted in the Central District of Clalit Health Services (a district of the largest health maintenance organization in Israel). All Clalit members in the district older than 50 years who underwent cataract surgery from 2000 to $2007(\mathrm{n}=12,984)$ and 25,968 age- and sex-matched controls comprised the sample. Electronic medical records of all patients in the study were reviewed. The main outcome measure was the prevalence of osteoporosis and the odds ratio of having osteoporosis among cataract patients compared with controls.

Results: Demographically, $41.8 \%$ were men with a mean age of $68.7 \pm 8.2$ years. A logistic regression model for osteoporosis showed that age, female sex, higher socioeconomic class, smoking, chronic renal failure, hyperthyroidism, rheumatoid arthritis, inflammatory bowel diseases, and cataract are all associated with increased prevalence of osteoporosis. Obesity is a protective factor for osteoporosis. In all age-groups, osteoporosis was more prevalent in cataract patients than in the control group.

Conclusion: Among other well-known risk factors, osteoporosis is associated with the presence of cataracts. Common pathophysiological associations with both conditions, such as calcium imbalance, hormonal abnormalities, and shared genetic predisposition, are discussed.

Keywords: cataract, osteoporosis, risk factors

\section{Introduction}

Epidemiologic studies on cataracts have suggested that it is a multifactorial condition with many risk factors. ${ }^{1}$ Research has recently highlighted the role of electrolyte imbalance in the development of cataracts. Calcium is of particular concern. Changes in calcium concentration might be an important factor in the development of cataracts. ${ }^{2}$ This cation is essential for various lens-fiber cell-metabolism processes. ${ }^{3}$ Proper calcium homeostasis is critical to lens clarity. Elevated calcium levels are related to numerous processes that contribute to alterations in the molecular structure of the lens and increased light scattering by the lens. ${ }^{4}$ It has been shown that lens calcium content correlates with opacity in cataractous human lenses. ${ }^{5}$

Calcium is also considered an important factor in the development of osteoporosis. Osteoporosis is known to be linked to calcium imbalance, even though serum calcium levels are usually normal in this condition. Various clinical conditions associated 
with abnormal calcium levels result in osteoporosis. ${ }^{6}$ The present study evaluated the prevalence of osteoporosis among 12,984 patients undergoing cataract surgery and the possible link between these conditions.

\section{Patients and methods}

The study took place in the Central District of Clalit Health Services health maintenance organization (HMO), a district of the largest HMO in Israel. The electronic medical records of all members aged 50 years and older who underwent cataract surgery from January 1, 2000 and who did not terminate their membership before December 31, 2007 were included $(n=12,984)$. Cataract patients who died or left the HMO during the study period $(n=2,251)$ were excluded.

Osteoporosis was defined by the International Classification of Diseases (ICD)-9 code for osteoporosis, a pathological fracture, a dual-energy X-ray absorptiometry report, or the use of osteoporosis medications. For each cataract patient in the study group, two members of the HMO who were matched in age and sex and did not undergo cataract surgery $(n=25,968)$ were randomly selected from all members of the HMO who were members of the HMO on January 1, 2000 and did not discontinue membership (for any reason, including death) before December 31, 2007. Data extracted on each patient included age, sex, marital status, socioeconomic class (low or other), area of living (rural or urban), and chronic diseases, being smoking, obesity, chronic renal failure, hyperthyroidism, rheumatoid arthritis, and inflammatory bowel diseases.

The study was approved by the institutional review board of Clalit Health Services. Informed consent was not required.

\section{Observation procedures}

The Clalit Health Services HMO maintains a chronic disease registry database, which includes information collected from a variety of sources, including primary care physician reports, medication-use files, hospitalization records, and outpatient clinic records. The methods of registry acquisition and maintenance have been described elsewhere. ${ }^{?}$

\section{Statistical analysis}

Univariate comparison of dependent and independent variables was conducted by chi-square test or one-way analysis of variance, as appropriate. Adjustment for age and sex was carried out. Multivariate logistic regression models were used to estimate the independent (adjusted) effect of independent variables in the model. The threshold for significance was $P<0.05$.
The data were analyzed using the SPSS statistical package (version 12; IBM, Armonk, NY, USA).

\section{Results}

A total of 12,984 patients who underwent cataract surgery during the study period were eligible. We examined various risk factors for osteoporosis for those patients and compared them to an age- and sex-matched control group from the population of the district $(n=25,968)$.

Demographically, $41.8 \%$ were men. The mean age in both the cataract and the control groups was $68.7 \pm 8.2$ years. No difference was found in other factors, including marital status, socioeconomic class, and living place, between the study and control groups (Table 1). Table 2 presents a comparison of diseases associated with risk of osteoporosis between the cataract and control groups.

We further performed a logistic regression model to evaluate the risk for osteoporosis (included in the model sociodemographic and clinical background). Age, female sex, higher socioeconomic class, smoking, chronic renal failure, hyperthyroidism, rheumatoid arthritis, inflammatory bowel diseases, and cataract were all associated with increased prevalence of osteoporosis. Obesity was found to be a protective factor for osteoporosis (Table 3). Men had a significantly higher incidence of osteoporosis with cataract in patients 75 years of age and older.

\section{Discussion}

We found a significant association between cataract and osteoporosis among women of all age-groups and in men older than 75 years. Smoking, ${ }^{8}$ obesity, ${ }^{9}$ chronic renal failure, ${ }^{10}$ hyperthyroidism, ${ }^{11}$ rheumatoid arthritis, ${ }^{12}$ inflammatory bowel diseases ${ }^{13}$ are well known to be associated with osteoporosis and have been reported on extensively. Obesity as a protective factor has already been reported. ${ }^{14}$ To the best of our knowledge, this is the first study to show this association.

Table I Comparison of demographics among patients undergoing cataract surgery versus controls

\begin{tabular}{llll}
\hline & $\begin{array}{l}\text { Cataract surgery } \\
\text { patients } \\
(\mathbf{n = 1 2 , 9 8 4 )}\end{array}$ & $\begin{array}{l}\text { Matched } \\
\text { controls } \\
(\mathbf{n}=\mathbf{2 5}, \mathbf{9 6 8})\end{array}$ & P-value \\
\hline Age, years & $68.7 \pm 8.2$ & $68.7 \pm 8.2$ & 1.0 \\
Males & $5,423(41.77 \%)$ & $10,846(41.77 \%)$ & 0.99 \\
Married & $7,253(55.9 \%)$ & $14,246(54.9 \%)$ & 0.06 \\
Low socioeconomic & $4,733(36.4 \%)$ & $9,428(36.3 \%)$ & 0.85 \\
class & & & 0.61 \\
Living in rural & $1,898(14.6 \%)$ & $3,731(14.4 \%)$ & \\
settlements & & & \\
\hline
\end{tabular}


Table 2 Comparison of diseases and chronic conditions associated with osteoporosis among patients undergoing cataract surgery versus controls

\begin{tabular}{llll}
\hline & $\begin{array}{l}\text { Cataract surgery } \\
\text { patients } \\
(\mathbf{n = 1 2 , 9 8 4 )}\end{array}$ & $\begin{array}{l}\text { Matched } \\
\text { controls } \\
\mathbf{( n = 2 5 , 9 6 8 )}\end{array}$ & OR (95\% CI) \\
\hline Smoking & $18.6 \%$ & $15.2 \%$ & $1.28(1.21-1.38)$ \\
$\begin{array}{l}\text { Obesity } \\
\text { Chronic renal }\end{array}$ & $24.3 \%$ & $21.2 \%$ & $1.20(1.13-1.25)$ \\
$\begin{array}{l}\text { failure } \\
\text { Hyperthyroidism }\end{array}$ & $1.7 \%$ & $9.1 \%$ & $1.34(1.25-1.44)$ \\
$\begin{array}{l}\text { Rheumatoid } \\
\text { arthritis }\end{array}$ & $1.6 \%$ & $1.5 \%$ & $1.12(0.95-1.33)$ \\
$\begin{array}{l}\text { Inflammatory } \\
\text { bowel diseases }\end{array}$ & $0.6 \%$ & $1.1 \%$ & $1.46(1.22-1.74)$ \\
\hline
\end{tabular}

Abbreviations: $\mathrm{OR}$, odds ratio; $\mathrm{Cl}$, confidence interval.

This section focuses on calcium imbalance as a common key event, hormonal abnormalities associated with both conditions, and shared ultrastructural abnormalities found in cataract and osteoporosis.

\section{Calcium imbalance}

Osteoporosis is a complex multifactorial disorder characterized by bone fragility and reduced bone quality. The current study provides evidence for the association between osteoporosis and cataract. However, the role of calcium in both conditions is complex. Both cataract and osteoporosis are associated with an imbalance in calcium, not necessarily detectable by simple calcium serum-level testing. Calcium is the most abundant mineral in the body. Over $99 \%$ of total body calcium is found in bone and teeth. A constant exchange exists between the calcium held in the bones and circulating calcium. Bone calcium can remain fairly consistent, with calcium being reabsorbed from the bone and deposited at

Table 3 Logistic regression model for odds ratio for osteoporosis (included in the model sociodemographic and clinical background)

\begin{tabular}{|c|c|c|}
\hline $\begin{array}{l}\text { Risk factors and } \\
\text { sociodemographics }\end{array}$ & OR $(95 \% \mathrm{CI})$ & $P$-value \\
\hline Age (for each year) & $1.018(1.015-1.022)$ & $<0.001$ \\
\hline Sex (female $>$ male) & I8.87 (I7.|10-20.8I) & $<0.00$ I \\
\hline Socioeconomic class (high $>$ low) & $1.47(1.39-1.56)$ & $<0.001$ \\
\hline Smoking & $1.24(1.13-1.35)$ & $<0.001$ \\
\hline Obesity & $0.71(0.67-0.76)$ & $<0.001$ \\
\hline Chronic renal failure & $1.08(0.98-1.20)$ & 0.12 \\
\hline Hyperthyroidism & $1.35(1.11-1.63)$ & 0.002 \\
\hline Rheumatoid arthritis & $2.44(20.1-2.97)$ & $<0.001$ \\
\hline Inflammatory bowel diseases & $1.28(0.9|-| .82)$ & 0.16 \\
\hline Cataract & $1.30(1.23-1.37)$ & $<0.001$ \\
\hline
\end{tabular}

Abbreviations: $\mathrm{OR}$, odds ratio; $\mathrm{Cl}$, confidence interval. similar rates. However, when blood serum calcium levels are constantly low, the body reabsorbs calcium into the blood from the bone faster than it can be deposited back, resulting in a loss of bone mass - osteoporosis. ${ }^{15}$

Although less than $1 \%$ of body calcium circulates in the blood, that level has vitally important roles in muscle contraction, nerve-impulse transmission, blood clotting, and cell metabolism. A calcium deficiency or difficulty with calcium absorption, even for short periods of time, can result in significant bone loss. This explains why elevated serum calcium levels frequently indicate a deficiency in total calcium. In osteoporosis, blood calcium levels are normal. ${ }^{6}$

The total blood calcium concentration is approximately 150 times greater than that of free calcium in human lenses, as determined by electrodes. ${ }^{16}$ It is also twice as high as the calcium concentration in the aqueous humor. These differences suggest that calcium is either sequestered in intracellular compartments, bound to extracellular components of the lens, or both.

Calcium has long been known to play a role in cataract formation. It is essential for various lens-fiber cell processes, including differentiation. ${ }^{17}$ Calcium homeostasis is critical to the clarity of the lens, ${ }^{18}$ and abnormal calcium content correlates with opacity in cataractous human lenses. ${ }^{5}$ Alterations in calcium homeostasis of the lens, which result in increased cytosolic calcium levels, might be an important factor in cataract formation, particularly cortical cataract, posterior subcapsular opacification, and even for the contraction of the lens capsule after cataract surgery. ${ }^{2}$

A decrease in external calcium causes lens swelling and opacification both in vitro ${ }^{19}$ and in vivo, ${ }^{20}$ while an increase in internal calcium is a feature of most cataractous lenses. The total calcium in human lenses with cortical cataracts was found to be four times higher than that in clear lenses. ${ }^{4}$ On the basis of multiple studies that compared clear and cataractous lenses, total calcium was found to be elevated in almost all cataracts by an average of $200 \%-300 \%$. Even pure nuclear cataracts have two to 26 times more total calcium than do clear lenses. ${ }^{4}$

Elevated calcium levels are related to numerous processes, including activation of proteases, ${ }^{21}$ inhibition of $\mathrm{Na} / \mathrm{K}$-adenosine triphosphatase (ATPase) activity, ${ }^{5}$ cell growth, protein synthesis, and calcium influx; disintegrative globulization; ${ }^{22}$ cell death; increased membrane permeability; and aggregation of proteins and lipids. ${ }^{23}$ All these factors could contribute to alterations in the molecular structure of the lens and increased light scattering by the lens. ${ }^{4}$ 


\section{Hormonal abnormalities associated with both osteoporosis and cataract}

Steroids represent one of the most studied endogenous or exogenous substances responsible for both osteoporosis and cataract. Several mechanisms have been proposed for steroid-induced posterior subcapsular cataracts, such as $\mathrm{Na} / \mathrm{K}$-ATPase inactivation, oxidative free radical damage, proteolysis, and inadequate energy production. ${ }^{24}$ Steroidinduced osteoporosis is the most frequent cause of secondary osteoporosis..$^{25}$ Osteoporosis occurs eventually in up to $50 \%$ of patients on long-term steroid therapy.

\section{Genetic predisposition for osteoporosis and cataract}

Differences in bone mineral density between individuals of the same age are largely attributable to genetic differences, not differences in environmental exposure. ${ }^{3}$ Remarkably, several of the genes thought to play a role in osteoporosis were recently targeted as possibly being linked to cataract development. ${ }^{26}$

\section{Intercellular matrix}

Collagen is a central component of the organic bone matrix, and has been discovered to be an essential component of the lens extracellular matrix (ECM). ${ }^{27}$ Some subtypes of collagen are suspected of being involved in the pathogenesis of osteoporosis, and were also demonstrated in the human lens: types I, IV, ${ }^{28} \mathrm{IX}$, and XVIII. ${ }^{27}$ Other components of the ECM, such as laminin ${ }^{29}$ and fibronectin, ${ }^{30}$ were found to be essential in both bone and lens function.

\section{Local transcellular level}

A multitude of cytokines, prostaglandins, and local growth factors were shown to be responsible for the communication between cells in the bone as well as in the lens, and incriminated in the pathology of osteoporosis and cataract, respectively. ${ }^{31}$ The list includes epithelial growth factor, fibroblast growth factor, transforming growth factor, ${ }^{29}$ the insulin-like growthfactor system, interleukins (ILs), particularly IL-1 and IL-6, tumor-necrosis factor alpha, and prostaglandin $\mathrm{E}_{2} \cdot{ }^{32}$ Studies have been conducted over two decades on the regulatory role of nitric oxide in bone metabolism, ${ }^{33}$ but only recently was this short-living agent demonstrated to be critical in lens epithelial cell processes. ${ }^{34}$

\section{Cellular level}

Polymorphism in the hormonal receptors could be a common source for osteoporosis and cataract. Vitamin D-receptor or estrogen-receptor ${ }^{35}$ genes are good candidates. LRP5, coding for the lipoprotein receptor-related protein $5,{ }^{36}$ should be highlighted too. Although the implication of gene polymorphism concerning bone morphogenetic protein 2 involved in the regulation of osteoblast differentiation is still controversial in osteoporosis pathogenesis, this protein was shown to be crucial in proper lens function. ${ }^{37}$

The strength of the current study is that it was based on a large community population. Potential limitations of our study must also be considered. Although detailed information on a multitude of potential confounders was collected and adjusted for, the authors cannot rule out the possibility that unmeasured confounders may explain the observed association.

In retrospect, there are inherent limitations to the study. This case-control study was based on the assumption that patients not undergoing cataract surgery do not have cataract. It is possible that some patients had cataract that had no clinical effect or did not undergo surgery for other reasons. This may have been a potential confounder. However, as the study population was relatively homogeneous, we believe that the results were not influenced significantly.

We selected controls that did not have cataract surgery. We did not want to limit the controls to HMO members who visited an eye clinic, since this might have introduced other ocular pathologies into the control group and led to various biases. However, because the accessibility to health services in Israel in general and in this district in particular is quite high, we assume that if the control patients had a visually significant cataract, they would have seen an ophthalmologist and been referred for cataract surgery.

Another potential limitation is that osteoporosis could have been diagnosed prior to the cataract surgery. There was no information on cataract subtypes in our study. Lens opacity can exist without symptoms, but is clinically relevant only if visual function is considerably decreased, ${ }^{38}$ requiring surgery. We included all cases requiring lens extraction. In the Israeli health care system, all patients in the study had the same access to cataract extraction. However, we cannot exclude potential bias because of the underestimation of cataract prevalence, which would lead to diluted risk

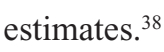

In conclusion, in a large cohort of 12,984 cataract patients undergoing cataract surgery and 25,968 controls, osteoporosis was significantly more prevalent among cataract patients. As so many epidemiologic risk factors for cataract have been identified, and currently there are no tested strategies for the primary prevention of cataract in the community, ${ }^{39}$ 
we suggest that future cataract research focus on the primary prevention of cataract. This may be achieved by performing more complex study designs looking at multiple factors that contribute to a single mechanism of cataractogenesis. ${ }^{40}$ The need to standardize exposure and outcome measurements will become more important as clinicians seek to better synthesize data from multiple studies.

\section{Disclosure}

The authors report no conflicts of interest in this work.

\section{References}

1. Hodge WG, Whitcher JP, Satariano W. Risk factors for age-related cataracts. Epidemiol Rev. 1995;17:336-346.

2. Mukai K, Matsushima H, Ishii Y, Obara Y. [Effects of calcium on lens epithelial cells in rabbits]. Nippon Ganka Gakkai Zasshi. 2006;110: 361-369. Japanese.

3. Seeman E. Pathogenesis of bone fragility in women and men. Lancet. 2002;359:1841-1850.

4. Tang D, Borchman D, Yappert MC, Vrensen GF, Rasi V. Influence of age, diabetes, and cataract on calcium, lipid-calcium, and proteincalcium relationships in human lenses. Invest Ophthalmol Vis Sci. 2003;44:2059-2066

5. Hightower KR, Hind D. Cytotoxic effects of calcium on sodium-potassium transport in the mammalian lens. Curr Eye Res. 1982;2:239-246.

6. Jamal SA, Leiter RE, Bayoumi AM, Bauer DC, Cummings SR. Clinical utility of laboratory testing in women with osteoporosis. Osteoporos Int. 2005;16:534-540.

7. Rennert G, Peterburg Y. Prevalence of selected chronic diseases in Israel. Isr Med Assoc J. 2001;3:404-408.

8. Daniell HW. Osteoporosis of the slender smoker. Vertebral compression fractures and loss of metacarpal cortex in relation to postmenopausal cigarette smoking and lack of obesity. Arch Intern Med. 1976;136 298-304.

9. Zhao LJ, Liu YJ, Liu PY, Hamilton J, Recker RR, Deng HW. Relationship of obesity with osteoporosis. J Clin Endocrinol Metab. 2007;92:1640-1646.

10. Stavroulopoulos A, Porter CJ, Roe SD, Hosking DJ, Cassidy MJ. Relationship between vitamin D status, parathyroid hormone levels and bone mineral density in patients with chronic kidney disease stages 3 and 4. Nephrology (Carlton). 2008;13:63-67.

11. Baliram R, Sun L, Cao J, et al. Hyperthyroid-associated osteoporosis is exacerbated by the loss of TSH signaling. $J$ Clin Invest. 2012;122: 3737-3741.

12. Lorbergs AL, Macintyre NJ. The International Classification of Functioning, Disability and Health (ICF) Core Sets: application to a postmenopausal woman with rheumatoid arthritis and osteoporosis of the spine. Physiother Theory Pract. 2013;29:547-561.

13. Azzopardi N, Ellul P. Risk factors for osteoporosis in Crohn's disease: infliximab, corticosteroids, body mass index, and age of onset. Inflamm Bowel Dis. 2013;19:1173-1178.

14. Chang CS, Chang YF, Wang MW, et al. Inverse relationship between central obesity and osteoporosis in osteoporotic drug naive elderly females: the Tianliao Old People (TOP) study. J Clin Densitom. 2013;16:204-211.

15. Yodfat Y. [What's new in postmenopausal osteoporosis]. Harefuah. 2007;146:134-139, 164. Hebrew.

16. Duncan G, Hightower KR, Gandolfi SA, Tomlinson J, Maraini G. Human lens membrane cation permeability increases with age. Invest Ophthalmol Vis Sci. 1989;30:1855-1859.

17. Wride MA. Cellular and molecular features of lens differentiation: a review of recent advances. Differentiation. 1996;61:77-93.
18. Gupta PD, Johar K, Vasavada A. Causative and preventive action of calcium in cataracto-genesis. Acta Pharmacol Sin. 2004;25: 1250-1256.

19. Owers J, Duncan G. The viability of the bovine lens in organ culture. Exp Eye Res. 1979;28:739-742.

20. Delamere NA, Paterson CA, Borchman D, Manning RE Jr. The influence of calcium on the rabbit lens sodium pump. Invest Ophthalmol Vis Sci. 1993;34:405-412.

21. Yoshida H, Murachi T, Tsukahara I. Limited proteolysis of bovine lens alpha-crystallin by calpain, a $\mathrm{Ca} 2+-$ dependent cysteine proteinase, isolated from the same tissue. Biochim Biophys Acta. 1984;798: 252-259.

22. Bhatnagar A, Dhir P, Wang LF, Ansari NH, Lo W, Srivastava SK. Alterations in the light transmission through single lens fibers during calcium-mediated disintegrative globulization. Invest Ophthalmol Vis Sci. 1997;38:586-592.

23. Bakas LS, Disalvo EA. Effect of encapsulated $\mathrm{Ca} 2+$ on the surface properties of curved phosphatidylcholine bilayers. Biochim Biophys Acta. 1991;1065:114-120.

24. Jobling AI, Augusteyn RC. What causes steroid cataracts? A review of steroid-induced posterior subcapsular cataracts. Clin Exp Optom. 2002;85:61-75.

25. Bartl R. [Update 2004. Osteoporosis - management - current status]. Krankenpfl J. 2004;42:232. German.

26. Rudolph G, Kalpadakis P, Bettecken T, et al. Spondylo-ocular syndrome: a new entity with crystalline lens malformation, cataract, retinal detachment, osteoporosis, and platyspondyly. Am J Ophthalmol. 2003;135:681-687.

27. Ihanamaki T, Pelliniemi LJ, Vuorio E. Collagens and collagen-related matrix components in the human and mouse eye. Prog Retin Eye Res. 2004;23:403-434.

28. Tang D, Borchman D, Yappert MC. Alpha-crystallin/lens lipid interactions using resonance energy transfer. Ophthalmic Res. 1999;31: $452-462$.

29. Wederell ED, Brown H, O'Connor M, Chamberlain CG, McAvoy JW, de Iongh RU. Laminin-binding integrins in rat lens morphogenesis and their regulation during fibre differentiation. Exp Eye Res. 2005;81: 326-339.

30. Rodan GA. Bone mass homeostasis and bisphosphonate action. Bone. 1997;20:1-4.

31. Shigemitsu T, Ishiguro K, Shimizu Y, Horiguchi M, Kasahara M, Arakaki S. Immunocytochemical features of lens after cataract tissue signalling molecules (growth factors, cytokines, other signalling molecules), cytoskeleton proteins, cellular and extracellular matrix proteins. Int Ophthalmol. 1999;23:137-144.

32. Raisz LG, Woodiel FN. Effects of selective prostaglandin EP2 and EP4 receptor agonists on bone resorption and formation in fetal rat organ cultures. Prostaglandins Other Lipid Mediat. 2003;71:287-292.

33. Wimalawansa SJ. Rationale for using nitric oxide donor therapy for prevention of bone loss and treatment of osteoporosis in humans. Ann N Y Acad Sci. 2007;1117:283-297.

34. Chamberlain CG, Mansfield KJ, Cerra A. Nitric oxide, a survival factor for lens epithelial cells. Mol Vis. 2008;14:983-991.

35. Gennari L, Merlotti D, De Paola V, et al. Estrogen receptor gene polymorphisms and the genetics of osteoporosis: a HuGE review. Am J Epidemiol. 2005;161:307-320.

36. Richards JB, Rivadeneira F, Inouye M, et al. Bone mineral density, osteoporosis, and osteoporotic fractures: a genome-wide association study. Lancet. 2008;371:1505-1512.

37. Belecky-Adams TL, Adler R, Beebe DC. Bone morphogenetic protein signaling and the initiation of lens fiber cell differentiation. Development. 2002;129:3795-3802.

38. Lindblad BE, Hakansson N, Philipson B, Wolk A. Metabolic syndrome components in relation to risk of cataract extraction: a prospective cohort study of women. Ophthalmology. 2008;115:1687-1692.

39. McCarty CA, Taylor HR. A review of the epidemiologic evidence linking ultraviolet radiation and cataracts. Dev Ophthalmol. 2002;35: 21-31.

40. Abraham AG, Condon NG, West Gower E. The new epidemiology of cataract. Ophthalmol Clin North Am. 2006;19:415-425. 


\section{Publish your work in this journal}

Clinical Ophthalmology is an international, peer-reviewed journal covering all subspecialties within ophthalmology. Key topics include: Optometry; Visual science; Pharmacology and drug therapy in eye diseases; Basic Sciences; Primary and Secondary eye care; Patient Safety and Quality of Care Improvements. This journal is indexed on
PubMed Central and CAS, and is the official journal of The Society of Clinical Ophthalmology (SCO). The manuscript management system is completely online and includes a very quick and fair peer-review system, which is all easy to use. Visit http://www.dovepress.com/ testimonials.php to read real quotes from published authors. 